研究

\title{
Spark Plasma Sintering of BCN Ceramics Derived from Pyridine-Borane Complex
}

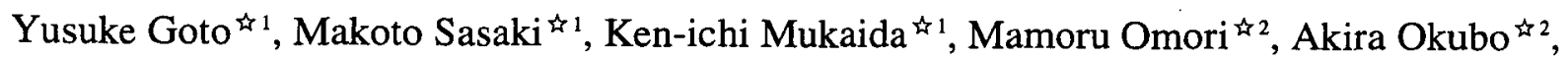

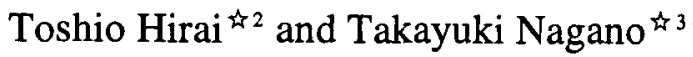 \\ 41 Division of Chemical and Material Engineering, Faculty of Engineering, Muroran Institute of Technology, 27-1 Mizumono-cho, \\ Muroran 050-8585. ${ }^{2}$ Institute for Materials Research, Tohoku University, 2-1-1 Katahira, Aoba-ku, Sendai 980-8577. \\ ${ }^{3} \mathrm{~J}$ apan Science and Technology Corporation, Japan Fine Ceramics Center 2F, 2-4-1 Mutsuno Atsuta-ku, Nagoya 456-0023.
}

Received July 27, 1998

\begin{abstract}
SYNOPSIS
BCN ceramic powder was prepared from pyridine-borane complex as starting material and spark plasma sintering (SPS) of the powder was performed on the condition at $2073 \mathrm{~K}$ for $10 \mathrm{~min}$ in a vacuum (heating rate: $90 \mathrm{~K} \mathrm{~h}^{-1}$, pressure: $39 \mathrm{MPa}$, diameter: $10 \mathrm{~mm}$ ). Crystallization of layered $\mathrm{BCN}$ ceramics was progressed by SPS. The interlayer spacings were $0.341 \mathrm{~nm}$ after SPS and $0.347 \mathrm{~nm}$ before SPS. The density was $2.43 \mathrm{mg} \mathrm{m}^{-3}$ after SPS and $2.40 \mathrm{mg} \mathrm{m}^{-3}$ before SPS. The hardness of $\mathrm{Hv}=65$ was obtained by SPS. The electrical conductivity in the direction parallel to the pressing direction was about $100 \mathrm{~S} \mathrm{~m}^{-1}$ and that in the direction perpendicular to the pressing direction was about 200 $\mathrm{S} \mathrm{m}^{-1}$ at room temperature.
\end{abstract}

KEY WORDS

pyridine-borane complex, BCN ceramics, SPS, hardness, conductivity

\section{Introduction}

Synthesis of BCN ceramics by the precursor method using organic material such as amine-borane etc. as starting material has been reported ${ }^{1-3)}$. The precursor method is excellent for controlling the composition of ceramics and larger quantities can be prepared by this method than by the CVD method ${ }^{4,5}$. The present authors have reported that amorphous BCN ceramics was prepared with heat treatment at $1273 \mathrm{~K}$ in an argon atmosphere from pyridine-borane complex as starting material and the boron had trigonally coordinated bonds ${ }^{6}$.

Because of less sinterability of the BCN ceramics such as graphite and h-BN, densification of the BCN ceramics by spark plasma sintering (SPS) was tried in this study and the properties such as density, hardness and electrical conductivity were examined.

\section{Experimental}

$100 \mathrm{ml}$ of xylene were added to $0.2 \mathrm{~mol}(20 \mathrm{ml})$ of pyridine-borane complex and were refluxed at $393 \mathrm{~K}$ for 24 $h$ in an argon atmosphere. After that, xylene, a solvent was removed and pyridine-borane derivative was obtained.

A formed body was produced from the obtained derivative by milling, sieving ( $<75 \mu \mathrm{m}$ ) and the CIP method ( $60 \mathrm{MPa})$. Before the SPS, the heat treatment was performed in electrical furnace at $1273 \mathrm{~K}$ for $2 \mathrm{~h}$ in an argon atmosphere to achieve the equilibrium composition of the $\mathrm{BCN}$ ceramics (heating rate: $250 \mathrm{~K} \mathrm{~h}^{-1}$, flow rate: $0.51 \mathrm{~min}^{-1}$ ). Further, the obtained specimen was heated at $2173 \mathrm{~K}$ for $2 \mathrm{~h}$ in an argon atmosphere (heating rate: $40 \mathrm{~K} \mathrm{~h}^{-1}$, flow rate: $1.01 \mathrm{~min}^{-1}$ ). The specimen obtained was milled and sieved $(<45 \mu \mathrm{m})$ and BCN ceramics powder was prepared.

SPS was performed on this powder specimen at $2073 \mathrm{~K}$ for $10 \mathrm{~min}$ in a vacuum using the Spark plasma sintering system (Sumitomo coalmining Co., Ltd., DR. SINTER SPS 1050). (heating rate: $90 \mathrm{~K} \mathrm{~h}^{-1}$, pressure: $39 \mathrm{MPa}$, diameter: $10 \mathrm{~mm}$ )

Density was measured by the pycnometer method and hardness was measured by Vickers hardness test (load: 1.96 $\mathrm{N}$, holding time: $20 \mathrm{sec}$ ). Electrical conductivity was measured from room temperature to $1073 \mathrm{~K}$ in an argon atmosphere by the direct current two-terminal method. It was measured at the plane perpendicular (I) and parallel (II) to the pressing direction.

\section{Results and discussion}

\subsection{The structure of $\mathrm{BCN}$ ceramics}

The results of chemical composition analysis of $\mathrm{BCN}$ ceramics prepared by SPS at $2073 \mathrm{~K}$ and by heat treatment at $2173 \mathrm{~K}, 1273 \mathrm{~K}$ are shown in Table 1 . The molar ratio was noted by using the nitrogen of 1 . The carbon content decreased after SPS by the decarbonization reaction and the boron content was maintained almost constant. Though the oxygen content is a very small, oxygen in the specimen after 
SPS slightly increased compared with the other cases.

The displacement curve of $\mathrm{BCN}$ ceramics during SPS is shown in Fig.1. A specimen was obtained of $10 \mathrm{~mm}$ in diameter and $5 \mathrm{~mm}$ in height and a slight increase in displacement was caused by thermal expansion up to 1900 K. About $20 \%$ rapid contraction by sintering occurred at temperatures above $2000 \mathrm{~K}$.

The results of X-ray diffraction patterns are shown in Fig.2. It was found that crystallization had progressed further for the specimen obtained by SPS than for the specimen obtained at $2173 \mathrm{~K}$, because the peak intensities of the (002) plane and the (100) plane increased slightly in comparison with the specimen obtained by heat treatment at $2173 \mathrm{~K}$, and the specimen of (b) plane (parallel to the pressing direction) by SPS ${ }^{7}$. The appearance of peaks due to $\mathrm{B}_{4} \mathrm{C}$ were clarified. The reason of the $\mathrm{B}_{4} \mathrm{C}$ formation is not understood. The X-ray diffraction pattern of the Fig.2 (a) serves as evidence of layer structure of $\mathrm{BCN}$ ceramics, and the difference of the X-ray intensities of (002) planes of the BCN ceramics between Fig.2 (a) and Fig.2 (b) gives authenticity to the layer structure of $\mathrm{BCN}$ ceramics. The interlayer spacings of the specimen of $0.347 \mathrm{~nm}$ before SPS and of $0.341 \mathrm{~nm}$ after SPS were observed. The SPS may be effective to the crystallization of the BCN ceramics. The interlayer spacing of $0.341 \mathrm{~nm}$ after SPS was larger than those of $0.336 \mathrm{~nm}$ of graphite and of $0.333 \mathrm{~nm}$ of h-BN.

The results of SEM observation are shown in Fig.3. Figure 3 (a) and 3 (b) are of the specimens obtained by

Table 1 Chemical composition of $\mathrm{BCN}$ ceramics (molar ratio).

\begin{tabular}{lccccc} 
& B & C & N & O & H \\
\hline SPS at $2073 \mathrm{~K}$ & 2.22 & 2.23 & 1 & 0.227 & \\
H. T. T. at $2173 \mathrm{~K}$ & 2.17 & 3.14 & 1 & 0.112 & $4.09 \times 10^{-2}$ \\
H. T. T. at $1273 \mathrm{~K}$ & 2.10 & 4.69 & 1 & 0.119 & 0.278 \\
\hline
\end{tabular}

H. T. T. ; heat treatment temperature

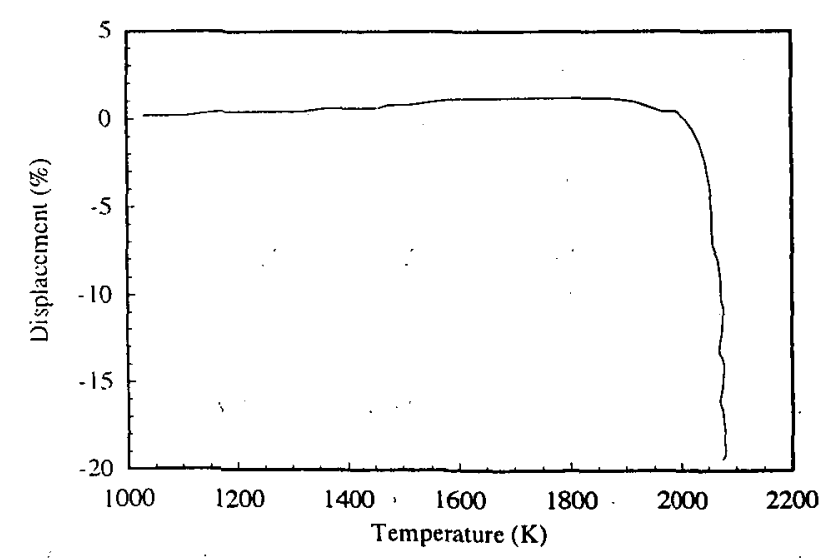

Fig.1 Displacement curve of BCN ceramics during SPS.
SPS at $2073 \mathrm{~K}$; (a) is parallel to the pressing direction and (b) is perpendicular to the pressing direction; (c) is the specimen obtained by heat treatment at $2173 \mathrm{~K}$ before SPS. The specimens after SPS had fewer pores compared with the specimen of heat treatment at $2173 \mathrm{~K}$ as shown in Fig.3.

As a result of density measurement, the density was found to be $2.43 \mathrm{mg} \mathrm{m}^{-3}$ after SPS, $2.40 \mathrm{mg} \mathrm{m}^{-3}$ by heat treatment at $2173 \mathrm{~K}$; and $2.24 \mathrm{mg} \mathrm{m}^{-3}$ by heat treatment at $1273 \mathrm{~K}$. The results of the density measurement show the densification was progressed by the SPS as shown in Fig.3. 3.2 Hardness and electrical conductivity of BCN ceramics

As a result of Vickers hardness measurement, the specimen obtained by heat treatment at $2173 \mathrm{~K}$ was $\mathrm{Hv}=38$, the plane perpendicular to the pressing direction of the specimen obtained by SPS was $\mathrm{Hv}=55$ and the plane parallel to the pressing direction was $\mathrm{Hv}=65$. It was found that the hardness of the specimen produced by SPS was greater than that produced by heat treatment. It was considered that the difference in hardness was caused either by densification by SPS or by the presence of $\mathrm{B}_{4} \mathrm{C}$ in the specimen after SPS. The plane parallel to the pressing direction showed larger hardness than that perpendicular to the pressing direction. It was guessed that a larger hardness on the parallel plane to the pressing direction than that on the perpendicular is due to a layer structure.

The electrical conductivities of the BCN ceramics obtained at $2073 \mathrm{~K}$ and $2173 \mathrm{~K}$ are shown in Fig.4. The specimen obtained by SPS showed higher electrical conductivity than other cases. Figure 4 shows metallic conduction in spite of the existence of semiconductive $\mathrm{B}_{4} \mathrm{C}$. The dispersed $\mathrm{B}_{4} \mathrm{C}$ may not affect the conductive mechanism of the metallic matrix specimen obtained by SPS. And the electrical conductivity increases with

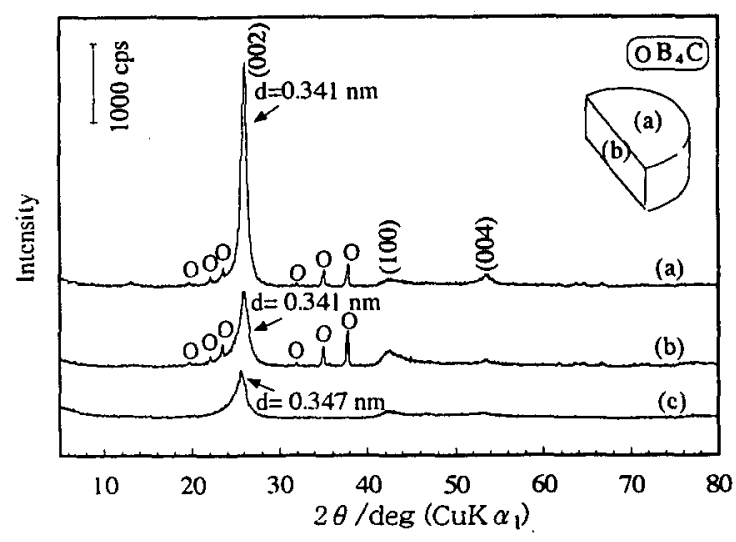

Fig.2 X-ray diffraction patterns of $\mathrm{BCN}$ ceramics.

(a) Perpendicular to the pressing direction of SPS specimen

(b) Parallel to the pressing direction of SPS specimen

(c) Specimen obtained at $2173 \mathrm{~K}$ by heat treatment 

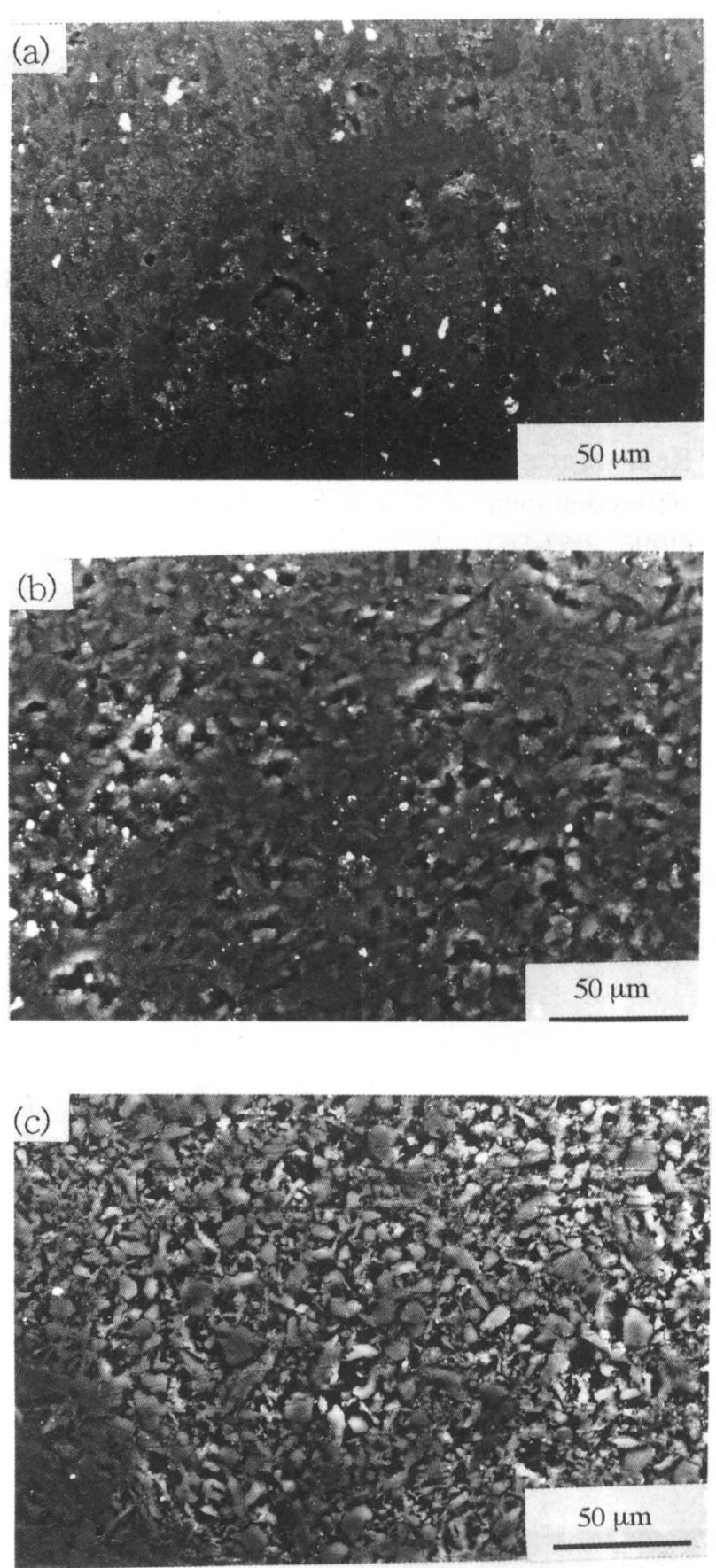

Fig.3 SEM photographs of BCN ceramics.

(a) Perpendicular to the pressing direction of SPS specimen

(b) Parallel to the pressing direction of SPS specimen

(c) Specimen obtained at $2173 \mathrm{~K}$ by heat treatment

increasing carbon content in the $\mathrm{BCN}$ ceramics. The chemical composition of the specimen obtained by heat treatment at $2173 \mathrm{~K}$ was $\mathrm{B}_{2.2} \mathrm{C}_{3.1} \mathrm{~N}$, and that of the specimen obtained by SPS was $\mathrm{B}_{2.2} \mathrm{C}_{2.2} \mathrm{~N}$. In spite of the less carbon content in SPS specimen, the specimen demonstrated larger conductivity. The densification due to be shortened interlayer spacing and the large grain-size caused by crystallization of SPS specimen may increase the

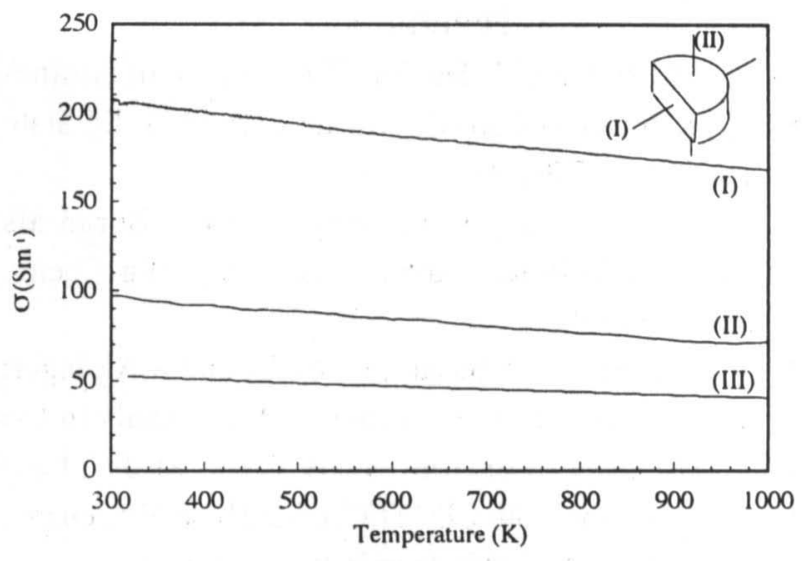

Fig.4 Electrical conductivity of $\mathrm{BCN}$ ceramics.

(I) Perpendicular to the pressing direction of SPS specimen

(II) Parallel to the pressing direction of SPS specimen

(III) Specimen obtained at $2173 \mathrm{~K}$ by heat treatment

conductivity. It may be concluded the plane perpendicular to the pressing direction (I) had higher electrical conductivity than the plane parallel to the pressing direction (II) because the direction of conduction was in a plane direction, the same as graphite.

\section{Conclusion}

Spark plasma sintering (SPS) was achieved on the BCN ceramic powder prepared from pyridine-borane complex. The following results were obtained:

(1) Crystallization progressed further by the densification of SPS and the layered structure was anisotropic.

(2) The density of the specimen obtained by SPS was 2.43 $\mathrm{mg} \mathrm{m}^{-3}$ and the specimen obtained before SPS was 2.40 $\mathrm{mg} \mathrm{m}^{-3}$ and the density of the specimen obtained by SPS was a little larger.

(3) The hardness perpendicular to the pressing direction was $\mathrm{Hv}=55$ and parallel was $\mathrm{Hv}=65$ because of the layer structure of the $\mathrm{BCN}$ ceramics.

(4) Electrical conductivity of the SPS specimen perpendicular to the pressing direction was $200 \mathrm{Sm}^{-1}$, and parallel was $100 \mathrm{Sm}^{-1}$ at $300 \mathrm{~K}$.

\section{Acknowledgments}

The authors wish to thank Dr. M. Suzuki of Hokkaido National Industrial Research Institute and Mr. T. Hoshi of Nittestu Cement Co. Ltd. for elemental analysis.

This research was supported in part by the Grant-in-Aid for Scientific Research from the Ministry of Education, Science, Sports and Culture under contract Nos. 10137201, 09229203 and 08243203 and a Sasakawa Scientific Research Grant. 


\section{Reference}

1) J.Bill, M.Frieß and R.Riedel: "Conversion of AmineBoranes to Boron Carbide Nitride", Eur. J. Solid State Inorg. Chem., 29(1992)195-212.

2) J.Bill, R.Riedel and G.Passing: "Amine-Boran als Precursoren für Borcarbidinitrid", Z. anorg. allg. Chem., 610(1992)83-90.

3) J.Bill, A.Kienzle, M.Sasaki, R.Riedel and F.Aldinger: "Novel Routes for the synthesis of Materials in the Quanternary System Si-B-C-N and Their Characterisation", 8th CIMTEC, edited by P.Vincenzini, (Elsevier Science Publishers B.V.), in press.

4) F.Saugnac, F.Teyssandier and A.Marchand:
"Characterization of C-B-N Solid Solutions Deposited from a Gaseousphase Between $900^{\circ} \mathrm{C}$ and $1050^{\circ} \mathrm{C}$ ", J. Am. Ceram. Soc., 75(1992)161-169.

5) T.M.Besmann: "Chemical Vapor Deposition in the Boron-Carbon-Nitrogen System", J. Am. Ceram. Soc., 73(1990)2498-2501.

6) Y.Goto, M.Sasaki and K.Mukaida: "Synthesis of B-NC Ceramics from Piperazine-Borane Complex", Key Engineering Materials 159-160(1999)347-352.

7) T.Komatsu, Y.Kakudate and S.Fujiwara: "Heat Resistance of a Shock-Synthesized B-C-N Heterodiamond", J. Chem. Soc., Faraday Trans., 92 (1996)5067-5071. 